\title{
Overview of Entertainment Management of Tourism Destinations: A Case Study of the Ladyboy Cabaret Show market in Phuket, Thailand
}

\section{Thirachaya Maneenetr}

Director of Center for Asia-Pacific Tourism Research, Faculty of Management Science, Khon Kaen University Email: thirachaya@kku.ac.th

\section{Thanh Ha Tran}

Student in Master Degree of Tourism Management, Faculty of Management Science, Khon Kaen University Email: cholly.pen@gmail.com

\section{Phatrada Sangsrirueng}

Student in Master of Business Administration Program, in Creative Tourism Management Faculty of Management Science, Khon Kaen University

Doi:10.5901/mjss.2014.v5n23p772

\begin{abstract}
This article aims to review literatures and previous researches about tourism destinations in the entertainment industry to develop suitable management guidelines for Ladyboy Cabaret Show in Phuket province. In terms of tourism, the Ladyboy Cabaret Show market is widely well-known and prominent and has the potential for a tourism market in Phuket province. It seems that the entertainment industry plays an important role in enhancing tourism in this province. Concerning management, the Ladyboy Cabaret Show market can be divided into three main parts which are, Destination Management Organizations Ladyboy Cabaret Show and tourists. As a tourism destination, the Ladyboy Cabaret Show market should focus on designing an image for Ladyboy Cabaret Show which continually impress and fascinate tourists.
\end{abstract}

Keywords: Ladyboy Cabaret Show, Entertainment Industry

\section{Introduction}

Tourism development is seen to be the path to enhance local economies and deliver more appropriate development to marginal social, cultural and physical environments (Thomas \&Augustyn, 2007). That is why developed and developing countries have supported tourism as a mechanic to drive their own economic and social-cultural system.

The Thai Tourism Industry has come a long way since we began promoting Thailand as a holiday destination in the early 1960s (Svetasreni, 2013). This country is comprised of subtropical scenery, profound Buddhist culture and unique folk custom, wonderful beaches and exciting outdoor activities which attract visitors from all over the world who come for tourism (Hou, 2012). As mentioned, the Thai economy depends heavily on the performance of its tourism industries (Chancharat, 2011). Thus, all the strategies are in line with the national economic and social development objectives of better income distribution nationwide, creating jobs in the rural areas, and creating a more balanced and harmonious society (Svetasreni, 2013).

Phuket province is located in the south of Thailand which is a favorite destination of many tourists who are all looking for the tropical paradise offered by Thailand as they escape the cold weather in their countries. This destination has a lot of tourism activities such as such as beach activities at Patong Beach and Phang Nga Bay, sightseeing in SinoPortuguese splendor shops or enjoying the nightlife with Ladyboy Cabaret Show. As a signature of Phuket, Ladyboy Cabaret Show is spectacular musical floor performance by ladyboys also called "Katoeys", which refer to either a transgender woman or an effeminate gay male in Thailand, which fascinate more and more international tourists.

Adeboye (2012) states that entertainment tourism is a popular niche of tourism in the world today. In terms of Phuket province, Ladyboy Cabaret Show is a tourism product which plays an important role in inducing tourists to visit Phuket province and should be arranged and managed appropriately. Moreover, Pearce \& Schänzel (2013) stated that destination management is especially important with regard to consideration of the stakeholders involved. This is 
consistent with what Fuchs \& Weiermair (2004) state, the fundamental goal of destination management is to assess the adequacy and effectiveness of the product, facilities, services and programs that altogether provide memorable tourism experiences for visitors.

Research problems were raised to determine guidelines for management of tourism destinations. Therefore, the researchers reviewed literature about entertainment and destination management to develop suitable management guidelines for Ladyboy Cabaret Show in Phuket province.

\section{Literature Review}

\subsection{Tourism Destination}

Hu and Ritchie (1993) stated that tourism destination is a package of tourism facilities and services, which like any other consumer product, is composed of a number of multi-dimensional attributes. This agrees with how the World Tourism Organization [UNWTO] (2007) defines a local tourism destination, which is a physical space in which a tourist spends at least one night. It includes tourism products such as support services and attractions and tourist resources. On tourism destination, Morrison (2012) states that the destination mix and the destination product are similar concepts. Every destination has four destination product components, physical products (attractions, facilities, transportation, and infrastructure), local residents, packages (a set of packages and programs which combine many elements of the total travel experience), and programs (events, festivals, and activities that are arranged or programmed for tourists). Additionally, Leiper (1995) also suggests that destinations are amalgams of tourism products, offering an integrated experience to consumers. Thus, the core of destinations is comprised of the six A's framework which includes: attractions, amenities, available packages, accessibility, activities and ancillary services (Buhalis, 2000).

These are basic factors which have significant impact on the travel-decision process. It can be said that these components, that are fundamental elements in a tourism destination, are to incorporate tourism products which are capable of meeting tourists' demands and to create memorable experiences for tourists (Xu, 2010).

\subsection{Entertainment industry}

Travelling in the past was quite expensive, though the meaning of holidays in the past was not the same as today (Adeboye, 2012). In the context of leisure and recreation, Leiper (1995) defines it as the theories and practice of travelling and visiting places for leisure related purposes while Swarbrooke et al. (2003) thought about tourism as the interwoven connection which comes up as a result of people travelling and temporarily staying at a destination outside their home for leisure or recreational purposes. That is why the entertainment industry attracts a whole lot of tourists seeking to have a fun time around the world (Adeboye, 2012).

In today's world, entertainment is defined as the more popular forms of the performing arts, such as variety shows and cabaret shows including singers, comedians, magicians, dancers as well as rock and pop concerts (Hughes, 2000), which produce a pleasurable and satisfying experience (Chen, 2012). In the social domain, entertainment can enhance the local people's quality of life by increasing their sense of belonging to a community and offering them more leisure experiences. In the economic domain, entertainment plays a role in diversifying the revenue source as well as directly increasing tourism revenue (Loi \& Pearce, 2012). Therefore, entertainment plays an important role in the tourism development of a destination.

From a marketing perspective, entertainment activities can be considered on both the supply and demand sides. Looking at things from a consumer's perspective requires determining who travels to events and why, and also who attends events while traveling (Getz, 2008). The job of the marketer or planner is to develop products to respond to consumers' wants and needs.

Iso-Ahola (1982) suggested that tourism is a dialectical process because it provides an outlet for avoiding something and for simultaneously seeking something. So, tourists have push factors in themselves to drive them to escape from a perceived mundane environment and to seek an evaluation of self, relaxation, prestige, regression, and enhancement of kinship relationships and facilitation of social interaction (Dann, 1981). Thus, it is necessary for destinations to become more and more sophisticated and exciting in terms of pull factors to attract tourists (Smith, 2006).

In conclusion, entertainment activities are tourism products which are developed to meet the needs of and make a memorable experience for tourists (Xu, 2010). In terms of tourism marketing, planners or marketers should not only focus on core products as entertainment but also consider supporting activities which can more broadly communicate the entertainment offered to tourists. Adeboye (2012) states that in choosing an attraction to market many things have to be 
considered, including what to market, targeted customers, location of attractions, seasonality of attractions, and promotion of attractions.

\section{Research Design}

\subsection{Research method}

The aim of this article is to review literature about tourism destinations of the entertainment industry and to apply it to the context of Ladyboy Cabaret Show in Phuket, Thailand - an attractive activity to fascinate a lot of international tourists in the Phuket destination.

\subsection{Research area}

In this study, the researchers focused on Phuket province - a popular tourist destination with many international tourists from various regions such as Europe, America, Russia, Asia and so on. This province is packed with a wide range of tourism services and amenities to facilitate tourists, such as five star hotels, famous restaurants with local food, shopping malls and night clubs. Nowadays, there are a lot of cabaret shows in which people who are ladyboys have major roles in the performances, such as, Phuket-Fantasea or Simon Cabaret, with creative contemporary Thai dramatic dance to attract more and more foreign tourists.

\section{Result}

\subsection{Background of Ladyboy Cabaret Show in Phuket, Thailand}

Phuket province has a lot of theaters featuring Ladyboy Cabaret Show such as Paradise Complex Patong, Simon Star Cabaret Show, Aphrodite Cabaret Show and especially Phuket Simon Cabaret Show which is prominent and widely wellknown. The cabaret shows comprise various performances from singers and dancers in musicals and comedy shows which reflect a multi-culture from around the world such as China, India, Russia and so on. The clever choreography and fabulous costumes make the shows splendid, colorful and fun. Moreover, Ladyboy Cabaret Show is not sex show; the show attracts a wide range of audiences from children to older persons. Therefore, Ladyboy Cabaret Show is entertainment activity for the entire family.

Apart from the splendid performances, ladyboys play an important role in the shows. Their ability and creativity is core to the success of the shows. With regard to ladyboys, they are fully integrated into and accepted by Thai society, even if they do not work in a cabaret show or performance. Actually, it is believed that the acceptance they enjoy in society is due to the nature of the surrounding Buddhist culture, which places a high value on tolerance. Thais believe that being a ladyboy is the result of transgressions in past lives (the notion of Karma), and that katoeys deserve pity rather than blame. Thus, ladyboys deserve to be treated with respect, since the courage it takes to live out who they want to be is nothing short of admirable. Therefore, Ladyboy Cabaret Show should be considered as an environment in which ladyboys can represent their abilities and gain equality in society.

Nowadays, the Ladyboy Cabaret Show market has a wide range of channels to reach international tourists. The official websites are in English and other foreign languages as well. These shows are also guaranteed by reviewers on Trip Advisors or other tourism websites. Tourists have several channels to make reservations for tickets such as by direct contact, travel agency or reservations online with affordable and fair pricing.

\subsection{Guidelines for the management of Ladyboy Cabaret Show in Phuket, Thailand}

In the entertainment world one can identify at least three groups of stakeholders: those who make the decisions about the entertainment, those who provide the entertainment and the audiences or consumers who experience the fruits of the other two parties' efforts (Pearce, 2008). Thus, the Ladyboy Cabaret Show market can be defined by three main parts which include Destination Management Organizations (DMO) who are the planners, involved public and private organizations or the owners of the theatres, as well as the Ladyboy Cabaret Show performances and the tourists as consumers who have expectations and who keep looking for memorable experiences during their trip. Therefore, it is important to identify each main part of the Ladyboy Cabaret Show market to develop guidelines for the management of the Ladyboy Cabaret Show in Phuket. 
First, we consider Destination Management Organizations or DMO. This concept is of a coalition of many organizations and interests working together towards mutual goals (Ritchie \& Hudson, 2009). The main role of a DMO consists in fulfilling marketing, promotional and sales tasks, as well as coordinating long-term destination planning and management since the consumer perceives and buys a destination as one integrated product (Elbe et al., 2009). As Formica \& Kothani (2008) state the global economy, changing market demographics, and emerging technology are forcing destination managers to adopt and implement proactive strategies to survive the competitive tourism environment.

Secondly, Ladyboy Cabaret Show seems to be a tourism product filled with colorful performances, skillful dancers and others. Smith (1994) states that the generic production begins with raw inputs, progresses through intermediate inputs and outputs, to final outputs, or the tourist's experience. Apart from that, Lew (1987) suggests destination attributes are an amalgam of the different elements that attract travelers, which seem to be the sum of beliefs, ideas, and impressions that a person has of a destination (Crompton (1979).

Thirdly, we refer to tourists who frequently perceive a destination as a whole, not only considered as a tourists' place but becomes a tourists' product (Manete \& Minghetti, 2006). They defined tourism destination as a collection of experiences which are ready to deliver, to meet tourists' demands and to create memorable experiences for tourists (Xu, 2010). On the other hand, tourists formulate images of alternative destinations, so image also emerges as a critical element in the destination choice process (Um and Crompton, 1999). This is consistent with the notion that information sources and the attributes of the different destinations form the basis for different image and experience expectations (Molina et al., 2010).

According to the previous researches, the core strategies for management of the Ladyboy Cabaret Show market for tourism in Phuket province as proposed as shown below:

- DMO should research tourists markets and divide segmentation appropriately

- DMO should focus on strategic marketing to communicate the image of Ladyboy Cabaret Show to tourists conveniently and reliably.

- $\quad$ DMO should promote the significance of Ladyboy Cabaret Show

- Ladyboy Cabaret Show should be more creative and impressive to attract tourists.

- Activities during the show should establish a connection between the tourists and the ladyboys

- Creating tourists' impression should be considered

\section{Conclusion}

The objective of this article was to review literatures and previous researches about tourism destinations in the entertainment industry to develop suitable management guidelines for Ladyboy Cabaret Show in Phuket province. In terms of tourism, the Ladyboy Cabaret Show market is widely well-known and prominent and has the potential for a tourism market in Phuket province. It seems that the entertainment industry plays an important role in enhancing tourism in this province. Concerning management, the Ladyboy Cabaret Show market can be divided into three main parts which are, Destination Management Organizations Ladyboy Cabaret Show and tourists. As a tourism destination, the Ladyboy Cabaret Show market should focus on designing an image for Ladyboy Cabaret Show which continually impress and fascinate tourists.

\section{References}

Adeboye, C.A. (2012). The Impact of Entertainment on Tourism. Case study: Agency Remarc in Greece. Central Ostrobothnia University of Applied. Retrieved from http://www.theseus.fi/bitstream/handle/10024/47217/Adeboye_Christopher.pdf?sequence=1.

Buhalis, D. (2000). Marketing the competitive destination of the future.Tourism Management, 21, 97-116.

Chancharat, S. (2011). Thai Tourism and Economic Development: The Current State of Research. Kasetsart Journal Social Science, 32 : $340-351$

Chen, C. (2012).Hierarchical linear relationship between the U.S. leisure and entertainment consumption.Technology in Society, 34(1), 44-54. http://dx.doi.org/10.1016/j.techsoc.2011.12.003.

Crompton, J.L. (1979). An assessment of the image of Mexico as a vacation destination and the influence of geographical location upon the image. Journal of Travel Research, 18 (4), 18-23.

Dann, G.M.S. (1981). Tourism Motivation: An Appraisal. Annals of Tourism Research, 8(21), 187-219. http://dx.doi.org/10.1016/01607383(81)90082-7.

Elbe, J., Hallén, L. and Axelsson, B. (2009), The destination-management organisation and the integrative destination-marketing process. International Journal of Tourism Research, 11: 283-296. doi: 10.1002/jtr.695.

Fuchs, M. \& Weiermair, K. (2004). Destination benchmarking: An indicator-system's potential for exploring guest satisfaction. Journal of 
Travel Research, 42 (3), 212-225.

Getz, D. (2008). Event tourism: Definition, evolution and research. Tourism management, 29, 403-428.http://dx.doi.org/10.1016/ j.tourman.2007.07.017.

Hou, Z. (2012). Tourism perception to Thailand of the Chinese mainland tourists

Content analysis on the We Media. Retrieved from http://www.nrct.go.th/th/Portals/0/data/\%E0\%B8\%A0\%E0\%B8\%95/2555/10/1stThaiChinese_doc/Chinese-Presenters/Hou\%20Zhiqiang\%20_English_.pdf

Hu, Y., \& Ritchie, J. R. B. (1993).Measuring destination attractiveness: A contextual approach.Journal of Travel Research,32(3), 25-34.

Hughes, H. (2000). Arts, Entertainment and tourism. Oxford: Butterworth Heinemann.

Iso-Ahola's, S.E. (1982). Toward a Social Psychological Theory of Tourism Motivation: A Rejoinder. Annals of Tourism Research, 9 , 256-262. http://dx.doi.org/10.1016/0160-7383(82)90049-4.

Leiper, N. (1995). Tourism Management. Collingwood, VIC: TAFE Publications

Lew, A.A. (1987). A framework for tourist attraction research. Annals of Tourism Research, 14, 553-575.

Loi, K. \& Pearce, P.L. (2012).Powerful stakeholders' view of entertainment in Macao's future. Journal of Business Research, 65(1), 4-12. http://dx.doi.org/10.1016/j.jbusres.2011.07.008

Manete, M. \& Minghetti, V.(2006). Destination management organizations and actors. In D. Buhalis \& C.D. Costa (Eds.), Toursm business frontiers: consumers, products and industry (pp.228-237). Oxford: Elservier Butterworth-Heinemann.

Molina, A., Gómez, M. and Martín-Consuegra, D. (2010). Tourism marketing information and destination image management. African Journal of Business Management, 4(5), 722-728.

Morrision, A. (2012). Destination Management and Destination Marketing: The Platform for Excellence in Tourism Destinations. Retrieved from http://www.lyxk.com.cn/fileup/PDF/2013-1-6.pdf

Pearce, P.L. (2008). Tourism and entertainment: boundaries and connections. Tourism Recreation Research, 33 (2) (2008), 125-130.

Pearce, D.G. \& Schänzel, H.A. (2013).Destination management: The tourists' perspective. Journal of Destination Marketing \& Management 2(3), 137-145.

Ritchie, J. R. B. and Hudson, S. (2009), Understanding and meeting the challenges of consumer/tourist experience research. International Journal of Tourism Research, 11: 111-126. doi: 10.1002/jtr.72.

Smith, S.L.J. (1994). The tourism product. Annals of Tourism Research, 21(3), 582-595.

Smith, M. (2006).Entertainment and new leisure tourism.In D. Buhalis\& C. Costa (Ed).Tourism Business Frontier.pp 220 - 227. Oxford: Elsevier Butterworth-Heinemann.

Svetasreni, S. (2013). World Travel Market (WTM) 2013 Thailand Networking Lunch. Retrieved from http://www.tatnews.org/world-travelmarket-wtm-2013/\#sthash.LgLm196c.dpuf

Swarbrooke, J. ,Beard, C.,Leckie, S.\&Pomfret, G.(2003). Adventure tourism the new frontier.Oxford: Elsevier Science

Thomas, R. \& Augustyn, M. (2007). (Eds), Tourism in the New Europe: Perspectives on SME Politics and Practices. Oxford: Elsevier.

Um, S. \&Crompton, J.L. (1999).The Roles of Image and Perceived Constraints at Different Stages in the Tourist's Destination Decision Process.In A Pizam, Y Mansfeld (Eds.).Consumer Behavior in Travel and Tourism (pp. 81-102). New York: Haworth Press.

World Tourism Organization.(2007). A Practical Guide to Tourism Destination Management. Madrid, Spain: World Tourism Organization.

$\mathrm{Xu}$, J.B. (2010). Perception of tourism products.Tourism Management, 31, 607-610. Retrieved from http://dx.doi.org/10.1016 lj.tourman.2009.06.011. 